\title{
Arquivos institucionais e a história do teatro no Brasil: o caso do Serviço Nacional de Teatro (SNT)
}

Institutional archives and the history of theater in Brazil: the example of the National Theater Service (SNT)

Angélica Ricci Camargo

Angélica Ricci Camargo

Pesquisadora do Programa Memória da Administração Pública Brasileira - MAPA/Arquivo Nacional.

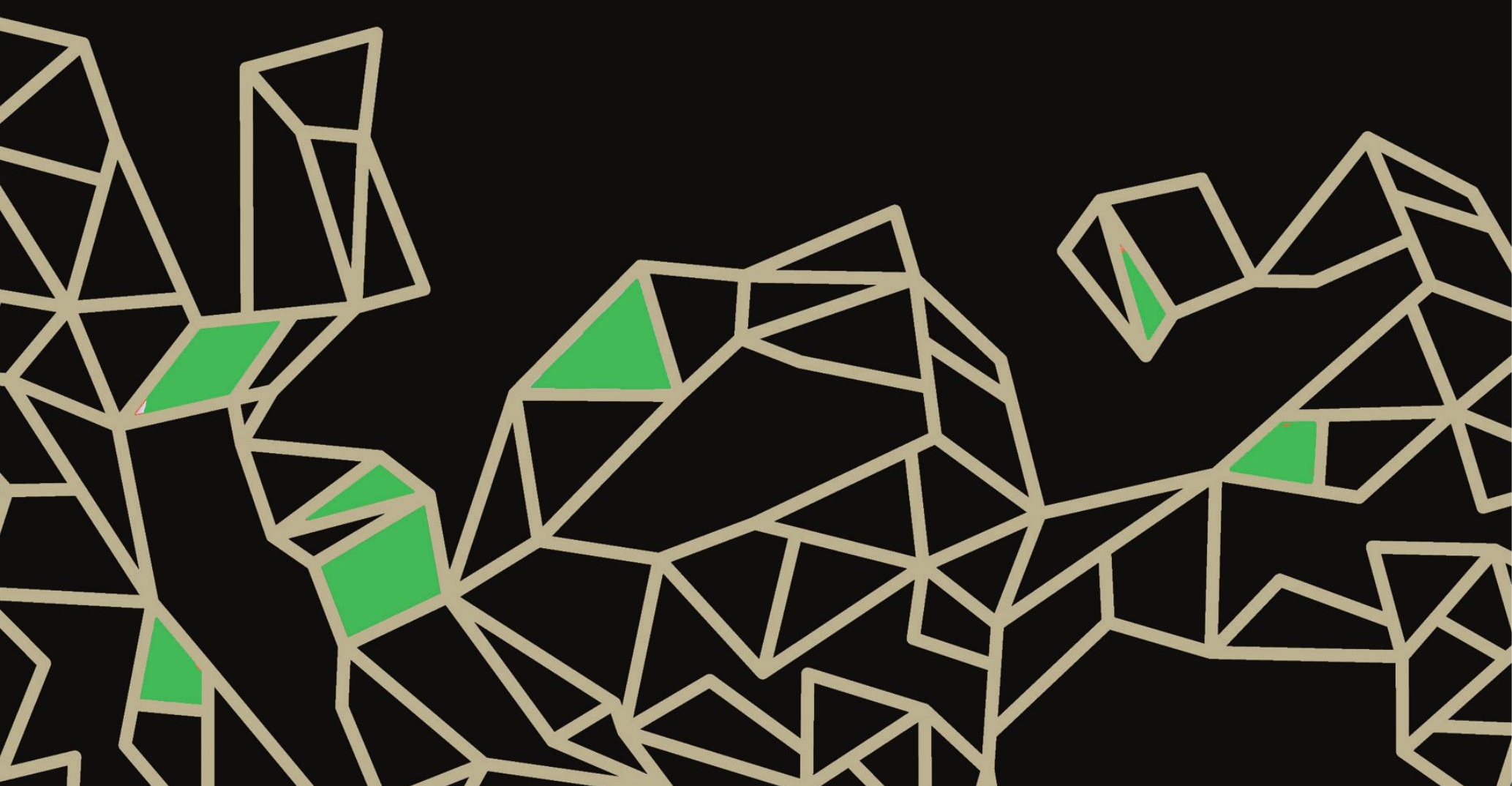




\section{Resumo}

Este artigo tem como objetivo refletir sobre os usos e as possibilidades de pesquisa em arquivos institucionais a partir dos nossos estudos sobre o Serviço Nacional de Teatro (SNT), órgão criado em 1937 com a finalidade de promover medidas de estímulo ao teatro. Além de favorecerem a reconstituição da sua trajetória administrativa, os documentos produzidos pelo SNT trazem informações sobre diferentes questões relativas ao setor teatral, como as organizações de classe, os aspectos ligados à produção e outros temas pouco estudados, que podem contribuir para repensar a história do teatro no Brasil.

Palavras-chave: Arquivo institucional, Serviço Nacional de Teatro, História do teatro, Brasil, Século XX.

\section{Abstract}

This article aims to reflect on the uses and possibilities of research in institutional archives based on studies on the National Theater Service (SNT), an institution created in 1937 with the purpose of promoting measures to stimulate theater. In addition to the reconstruction of its administrative history, the wide variety of documents produced by the SNT provides information on different issues related to the theatrical sector, such as class organizations, aspects of the theatrical production and other subjects, which can contribute to rethinking the Theater History in Brazil.

Keywords: Institutional archive, National Theater Service, History of theater, Brazil, Twentieth century.

Refletir sobre a documentação relativa ao Serviço Nacional de Teatro (SNT) é refletir sobre as nossas pesquisas, que a elegeram como fonte privilegiada, mas não exclusiva, da análise das primeiras décadas da trajetória do órgão, mais especificamente de 1937 a 1964 (CAMARGO, 2011, 2017).

O acervo do SNT integra o Arquivo Institucional da Fundação Nacional de Artes (Funarte), custodiado pelo Centro de Documentação (Cedoc), localizado no Rio de Janeiro. Encontra-se aberto para consulta, embora não esteja totalmente tratado. 
Ao retratar a vasta gama de atribuições acumuladas pela repartição ao longo do tempo, os documentos produzidos pelo SNT elucidam aspectos como a relação entre o órgão e as organizações de classe, os debates e as demandas do setor teatral, os custos de produção, as modalidades de financiamento e outros temas ainda pouco explorados pelos pesquisadores. Tais questões podem ser atribuídas, em grande parte, à "topografia de interesses" que norteou a escrita da história do teatro no Brasil, que, por muitos anos, concentrou a atenção na dramaturgia e nas trajetórias artísticas de atores e atrizes, e priorizou determinados tipos de fontes, como os textos encenados, as críticas publicadas em jornais, programas de espetáculos e depoimentos (CERTEAU, 2000, p. 67; PATRIOTA, 2008, p. 39).

Esse panorama tem se alterado nas últimas décadas com trabalhos acadêmicos originados em diferentes áreas, como Artes Cênicas, História e Letras. Sobre esse conjunto, verifica-se um renovado interesse pela história de artistas e gêneros que foram excluídos dos cânones consagrados, como a revista, e contribuições que redimensionaram o processo de modernização do teatro brasileiro. Outro destaque cabe aos estudos sobre experiências realizadas fora do eixo Rio de Janeiro-São Paulo, sobre críticos, revistas de teatro, escolas, associações e entidades de classe, relacionamento entre teatro e poder, entre outros temas.

Um indicador significativo dessa expansão pode ser observado na mais recente obra de caráter geral voltada para a história do teatro brasileiro, coordenada pelo professor João Roberto Faria e publicada em dois volumes em 2012 e 2013. Apesar das lacunas e limites ${ }^{1}$, o empreendimento representou um esforço sem precedentes em termos historiográficos, pela diversidade de assuntos tratados e pelos profissionais envolvidos (FARIA, 2012, 2013).

Essa ampliação de objetos e perspectivas de estudos ocorre paralelamente, mas não em igual proporção, a uma busca por fontes inéditas, sobretudo, em arquivos privados, muitos deles custodiados em instituições públicas, como o Cedoc/Funarte ou o Centro de Documentação Teatral da Universidade de São Paulo.

1 Cf. Mostaço (2015). 
Nesse sentido, vale assinalar o crescimento de debates acadêmicos acerca dos acervos teatrais, ainda que sejam poucas as menções sobre as possibilidades de pesquisa oferecidas pelos arquivos institucionais e a sua utilização para além da análise de determinado órgão público ou de uma atividade por ele desenvolvida (CANTANHEDE; FONTANA, 2013; RABETTI; MACIEL, 2012; SEMINÁRIO DE PRESERVAÇÃO DE ACERVOS TEATRAIS, 2015). Um exemplo disso pode ser visto no livro Na cena paulista, o teatro amador, coordenado por Roseli Figaro, no qual foram utilizados os processos produzidos pelo Serviço de Censura do Departamento de Diversões Públicas do Estado de São Paulo, para mapear os grupos amadores, os textos encenados e outros aspectos do "circuito cultural alternativo e popular" de São Paulo entre 1927 e 1945 (2008, p. 14).

Partindo dessas considerações gerais e de algumas questões surgidas em nossas pesquisas, faremos uma breve reflexão sobre a documentação do SNT, sem a pretensão de adentrar em discussões conceituais sobre fontes ou sobre a especificidade dos arquivos para a história do teatro ${ }^{2}$. Nosso objetivo consiste em apresentar, em linhas gerais, a história administrativa do seu produtor, "condição essencial para apreciação desse conjunto documental" (DUCHEIN, 1986, p. 17). E, em uma segunda etapa, atentar para as características e para a diversidade de informações contidas nesses documentos, especialmente nos processos, seus usos e contribuições para os estudos sobre a história do teatro no Brasil.

\section{A trajetória administrativa do SNT (1937-1964)}

O SNT foi criado pelo Decreto-Lei no 92, de 21 de dezembro de 1937, durante o primeiro governo de Getúlio Vargas (1930-1945). A sua existência deve ser entendida, em primeiro lugar, como parte das medidas centralizadoras promovidas pelo Estado brasileiro pós-1930, que buscou imprimir a sua distinção em todos os campos ligados ao trabalho de dominação e concebeu a cultura como "negócio oficial" (MICELI, 2001, p. 1998). E, igualmente, no interior da estruturação de órgãos e de iniciativas realizadas sob a esfera

2 Cf. Picon-Vallin (2012). 
do Ministério da Educação e Saúde (MES), conduzido por Gustavo Capanema entre 1934 e 1945.

Existe uma bibliografia extensa sobre a relação entre o governo e os intelectuais, a trajetória dos órgãos e a ideologia construída e difundida pelo Estado Novo, fase mais autoritária do governo Vargas, iniciada no final de 1937. Escapa a este artigo discutir essa bibliografia, no entanto, decorre de sua leitura a impossibilidade de identificação da elaboração de uma política para a cultura no singular, pois as ações oficiais dialogaram com questões e grupos, por vezes divergentes, ligados a cada área definida como objeto de atenção oficial nesse momento (CAMARGO, 2017, p. 36).

No caso do teatro, a instalação da Comissão de Teatro Nacional em 1936, e do SNT no ano seguinte, além de se constituir como parte de um conjunto de iniciativas governamentais, também atendeu às demandas de muitos profissionais teatrais, que viam a intervenção do governo como solução para os diferentes problemas enfrentados pelo setor (CAMARGO, 2011).

A Comissão de Teatro Nacional, instituída por Portaria de 14 de setembro de 1936, vigorou por pouco mais de um ano e reuniu personalidades teatrais e intelectuais, que discutiram diversos aspectos do fazer teatral. Seus trabalhos resultaram na publicação de obras sobre teatro, subvenções e promoção de espetáculos.

O SNT, órgão que a sucedeu, teve suas atribuições definidas pelo Decreto-Lei no 92, que consistiam em: estímulo à construção de teatros; organização ou amparo a companhias de teatro declamatório, lírico, musicado e coreográfico; orientação e auxílio a grupos amadores; incentivo ao teatro para crianças e adolescentes; promoção do ensino teatral; estímulo à produção de obras de teatro de todos os gêneros; inventário da produção brasileira e portuguesa; e tradução e publicação de peças teatrais (BRASIL, 1937, p. 364).

Entre os assuntos que cabiam ao SNT, figuravam, portanto, aqueles que envolviam questões materiais, como a falta de casas de espetáculos, e de ordem artística; como a publicação de peças ou a preparação de atores. Também vale ressaltar a noção abrangente de teatro, que abarcava domínios atualmente considerados em sua própria especificidade, como a ópera (teatro lírico) e a dança (coreografia). 
A partir do período democrático, iniciado com a deposição de Getúlio Vargas em outubro de 1945, o órgão passou por uma série de transformações que se articularam com as mudanças políticas e com as mutações ocorridas na esfera da administração pública federal.

Em 1953, no segundo governo de Getúlio Vargas, a pasta da Educação e Saúde foi dividida e deu origem ao Ministério da Educação e Cultura (MEC). Com a presença na denominação de um Ministério, a administração da cultura recebeu certo destaque, pelo menos em termos simbólicos. Na prática, a instabilidade política e as sucessivas alterações de ministros não propiciaram a concretização de um projeto para a área e apenas em 1961 uma política foi esboçada, com a criação do Conselho Nacional de Cultura no breve governo de Jânio Quadros (CAMARGO, 2017, p. 104, 254).

As instituições criadas na década de 1930 continuaram suas atividades, mas suas trajetórias, tal como a atenção conferida pelos governos seguintes aos setores culturais, tomaram diferentes rumos.

A cena teatral passou por um processo intenso de modificações, conhecido como modernização teatral, principiado, sobretudo, pelas experiências realizadas no final dos anos 1930 por conjuntos amadores. Tais experiências consolidaram-se no terreno profissional na década seguinte, abrindo caminho para o surgimento de companhias, dramaturgos, escolas, organizações de classe e até de outra crítica - com a coexistência das práticas teatrais novas com as até então predominantes, estas passaram a ser denominadas "antigas" ou "velhas." No bojo dessas mudanças, apareceram projetos políticos responsáveis por conceber o teatro como um instrumento de transformação social, tornando o período um dos mais estudados da historiografia teatral (Ibid., p. 2; GUINSBURG; PATRIOTA, 2012).

As administrações do SNT dialogaram com as questões que atravessaram o campo teatral, como analisamos em nossos trabalhos. Em termos de estrutura, inicialmente, o órgão contava com um diretor, uma secretaria e uma biblioteca. Criou-se, em 1939, o Curso Prático de Teatro e, no ano seguinte, a primeira companhia oficial, a Comédia Brasileira, que existiu até 1945. A partir da década de 1950, novos organismos foram estabelecidos, como a Seção Técnica, a Comissão de Teatro Infantil, a Comissão de Teatro Amador, a Companhia Dramática Nacional e as Delegacias nos estados do Rio Grande 
do Norte e da Bahia. Outros mudaram de nome, como a Secretaria, a qual virou Seção Administrativa, e o Curso Prático, que passou a ser chamado de Conservatório Nacional de Teatro em 1953. Em 1951, foi instituído o Conselho Consultivo de Teatro, congregando representantes de entidades e organizações de classe, como a Sociedade Brasileira de Autores Teatrais (SBAT), os Sindicatos dos Atores Teatrais, Cenógrafos e Cenotécnicos do Rio de Janeiro e de São Paulo, a Associação Brasileira de Críticos Teatrais (ABCT), a Associação Brasileira de Proprietários de Circo e Empresários de Diversões, a Associação Brasileira de Empresários Teatrais, a Associação Paulista de Críticos Teatrais, a Associação de Cronistas Teatrais de Pernambuco, entre outras. Esse Conselho, vigente até 1964, tinha a finalidade de deliberar sobre as subvenções, principal atividade empreendida pelo órgão desde o princípio de sua história (CAMARGO, 2017).

Em 1958, o Decreto o 44.318, de 21 de agosto, aprovou o primeiro regimento do órgão, composto por seção técnica, seção administrativa, biblioteca, museu e pelo Conservatório Nacional de Teatro.

No que se refere às competências, o regimento acrescentou e retirou atribuições, como a da construção de teatros. Outro item suprimido do Decreto de 1958 foi o relacionado ao inventário da produção brasileira e portuguesa, substituído por um que previa a organização do registro da produção teatral brasileira e estrangeira. As competências incorporadas foram associadas ao intercâmbio teatral no Brasil e no exterior, à instituição de museu e de biblioteca especializados, ao incentivo e desenvolvimento do teatro ambulante e à criação de cursos de teatro (BRASIL, 1958, p. 18801).

Apesar das inovações, o Decreto no 44.318 não mencionou estruturas existentes, como o Conselho Consultivo de Teatro, a Comissão de Teatro Social, o Teatro Nacional de Comédia, citados somente como competência, e as delegacias, criadas gradativamente em diversos estados.

Outro ato importante relacionado ao SNT foi o Decreto no 43.928 de 26 de junho de 1958, responsável por instituir a Campanha Nacional de Teatro. A Campanha tinha como objetivo promover o aprimoramento do teatro no país, e dispunha de um fundo próprio, que resultou em um aumento significativo do orçamento do SNT (BRASIL, 1958a, p. 14534). 
O primeiro diretor do órgão, nomeado em agosto em 1938, foi o dramaturgo, crítico e ex-presidente da SBAT, Alexandre Abadie Faria Rosa. Dentre os diretores que o sucederam até 1964, nomes como Carlos Alberto Nóbrega da Cunha, Thiers Martins Moreira, Aldo Calvet, Adonias Aguiar Filho, José César de Andrade Borba, Edmundo Moniz, Clóvis Garcia e Roberto Freire.

Ao lado deles, funcionários admitidos para trabalhos administrativos ou especializados, como Tomás Santa Rosa, Maria Clara Machado, Sábato Magaldi, Augusto de Freitas Lopes Gonçalves, Gustavo Dória, Sérgio Cardoso, Bibi Ferreira, Gianni Ratto e José Renato. E, ainda, os representantes das organizações teatrais convocados para a participação no Conselho Consultivo de Teatro e na Comissão Extraordinária de Auxílio Especial, existente entre 1962 e 1963, como Américo Garrido, Décio de Almeida Prado, Luiz Iglesias, Daniel Rocha, Luiz Olimecha, Sandro Polloni, entre outros, o que fez da instituição um lugar privilegiado de debates da cena e do campo teatral.

Após 1964, ocorreram novas modificações que fogem ao escopo deste estudo. No entanto, cabe ressaltar a transformação do órgão em Instituto Nacional de Artes Cênicas (Inacen) em 1981, e em Fundação Nacional de Artes Cênicas (Fundacen) em 1987.

A Fundacen foi extinta em 1990, pela Lei oㅜ 8.029 de 12 de abril, transferindo seus acervos, dotações orçamentárias, direitos e obrigações, tais como os da Fundação Nacional de Arte (Funarte) e os da Fundação Cinema Brasileiro (FBC) para o Instituto Brasileiro de Arte e Cultura (IBAC), estabelecido pelo mesmo ato. Em 1994, a Medida Provisória o 610 alterou a denominação do IBAC para Funarte, instituição atualmente responsável pela documentação acumulada de diferentes órgãos que compõem o seu Arquivo Institucional (FONSECA, 2007, p. 8-9).

\section{O acervo do SNT: características gerais, usos e possi- bilidades de pesquisa}

Não existe um instrumento de pesquisa relativo ao Arquivo Institucional da Funarte no que se refere ao acervo do SNT. No caso dos processos, há uma listagem com informações sobre o assunto e o interessado até $o$ ano de 
1959, facilitando o trabalho de pesquisadores na seleção das fontes, dado o volume desse material.

Desconhecemos os procedimentos de arquivamento do órgão ao longo de sua trajetória e as suas alterações realizadas em períodos posteriores, como a retirada de itens. Essas questões refletem a historicidade das práticas arquivísticas e remetem às próprias transformações da administração pública brasileira (COOK, 1998) ${ }^{3}$. Na impossibilidade de realizar um estudo mais aprofundado, todas as considerações seguintes são derivadas da nossa experiência direta de pesquisa e estão sujeitas, portanto, a generalizações e imprecisões.

Os documentos do SNT estão organizados em caixas e pastas divididas cronologicamente por tipos: planos de atividades, listas de auxílios, relatórios, correspondências, portarias, editais e processos. Existem, também, pastas relacionadas a estruturas específicas, como a do Conselho Consultivo de Teatro, a da Companhia Dramática Nacional e outra denominada "SNT - Histórico 1937/1940", de composição heterogênea. Essa documentação encontra-se em grande parte preservada, ainda que possamos apontar lacunas, que foram contornadas ou problematizadas com a utilização de outras fontes.

A leitura desse conjunto permitiu reconstituir sumariamente a história administrativa e o cotidiano burocrático da instituição a partir das perspectivas abertas pelas pesquisas de Victor Hugo Adler Pereira (1998), as quais assinalaram o papel do órgão nas transformações assistidas nos palcos brasileiros e merecem maior atenção, pois nossas propostas se limitaram a oferecer um quadro geral das atividades, tomando como objetos privilegiados o relacionamento do órgão com as organizações teatrais e a concessão de subvenções (2011, 2017).

Ao estabelecermos tais marcos, separamos as fontes em dois grupos. O primeiro, composto pelas portarias, planos de atividades, relatórios, listas de auxílio e editais, foi pesquisado e analisado integralmente; enquanto no segundo, formado pela correspondência e pelos processos, operou-se uma

3 Inicialmente, o Arquivo do SNT ficava dentro da Secretaria, a cargo de um funcionário específico, como indicam algumas portarias de nomeação. Em 1954, o Arquivo tornou-se parte da Seção Administrativa, junto com a Secretaria, o Protocolo, a Portaria e o Almoxarifado, estrutura que se manteve até, pelo menos, o ano de 1964. 
seleção, priorizando os documentos concernentes a estruturas do SNT, sua relação com as organizações e entidades de classe e os pedidos de subvenção de determinadas companhias e grupos profissionais de gêneros e perfis distintos.

Dentre os tipos de documentos mencionados, cabe chamar atenção para os processos referentes à subvenção, que já foram utilizados como fonte complementar em trabalhos monográficos sobre companhias, grupos e categorias artísticas. Esses processos contêm uma variada gama de informações, pois nos pedidos de amparo os requerentes enumeravam dados como elenco, repertório, gastos com a produção de espetáculos, salários de artistas e técnicos, valor do aluguel dos edifícios teatrais, número de representações, excursões, atividades realizadas, preços de ingressos, esboços de práticas de formação de público, entre outros aspectos dificilmente encontrados em colunas teatrais, programas ou arquivos privados.

Entre os pesquisadores que se valeram desses documentos, podemos citar Tania Brandão que, preocupada com a "História do Espetáculo no sentido de ser uma história do fazer, reconhecendo-se a materialidade desta prática social" (2009, p. 30), examinou elementos como os custos de produção e os auxílios recebidos do SNT na etapa de formação da Companhia Maria Della Costa, objeto de seu estudo. Ao tratar da disputa pelas verbas oficiais distribuídas pelo órgão, e autora também evidenciou as tensões que cercaram o advento do teatro moderno no Brasil, questionando as modificações do setor teatral que não se realizaram continuamente e "em progresso" como muitas vezes foram retratadas.

Fabiana Fontana (2014), em sua tese sobre o Teatro do Estudante do Brasil (TEB), buscou compreender o surgimento e a manutenção do grupo, atentando para as estratégias usadas pelo seu criador, o diplomata Paschoal Carlos Magno, para conseguir o apoio governamental, de importância crucial para o desenvolvimento de suas atividades no contexto de modernização teatral. Além disso, a pesquisadora utilizou os processos com pedidos de subvenção de grupos amadores de várias partes do país para analisar suas demandas, destacando a criação do SNT "como uma das principais causas para a constituição do amadorismo como campo" no Brasil (p. 334). 
Paulo Merisio (2013), em artigo sobre a história dos circos-teatros, utilizou os processos para estudar o percurso dos artistas circenses, especialmente o repertório, e mostrar como a produção teatral desta categoria se articulava com a das companhias de comédias mais tradicionais.

De forma geral, esses processos não são padronizados e não seguem uma ordem, seja da solicitação até o parecer final ou o inverso. Verificou-se, também, a ausência de parte do conteúdo em alguns casos pesquisados, e até exemplares dos quais restou apenas a capa. Outro tipo de procedimento comum encontrado foi o da anexação de processos de acordo com o assunto ou o interessado, que resultou na junção de documentos de datas diferentes, nem sempre relacionados a uma mesma petição.

Apesar da variação observada nesses anos, grosso modo, esses processos eram abertos e protocolados a partir do pedido na Secretaria, onde eram realizados o exame da demanda e a verificação das informações prestadas. Em seguida, o processo era dirigido para o diretor e/ou para os organismos decisórios, o Conselho Consultivo de Teatro ou a Comissão Extraordinária de Auxílio Especial, responsáveis pelo parecer com a proposta de auxílio ou com a recusa da solicitação.

A proposta era enviada para a aprovação do ministro e feita de forma individual ou em conjunto ${ }^{4}$. Após a concordância do ministro, o processo era remetido para outras repartições, como a Divisão de Orçamento do MES/ MEC ou a Diretoria de Despesa Pública do Tesouro Público, responsáveis pela autorização do pagamento, o qual parece ter sido centralizado posteriormente pela Campanha Nacional de Teatro.

Depois da utilização da verba recebida, cabia aos contemplados a prestação de contas, para qual, às vezes, era aberto um processo distinto. A prestação, composta pelos documentos comprobatórios dos gastos efetuados com a verba recebida, era analisada pela Secretaria, responsável por finalizar o processo e enviá-lo ao Arquivo.

Para a compreensão desses processos, além do itinerário percorrido, outros documentos produzidos pelo SNT são imprescindíveis, embora em alguns casos contenham dados divergentes: os editais, as atas do Conselho

4 Nos primeiros anos, a concessão de auxílios também ficava condicionada à aprovação do presidente da República. 
Consultivo de Teatro e da Comissão Extraordinária de Auxílio Especial e as listas de auxílios.

Os editais, lançados em 1939 e de 1953 a 1963, estabeleceram as categorias participantes e as condições de concorrência aos auxílios. Dentre elas figuravam diferentes informações, como repertório e elenco, exigências legais e, em algumas ocasiões, artísticas. Exemplo disso é o edital para a realização de convênio de 1958, que determinou a representação de peças de "nível artístico e cultural," avaliadas pelos membros do Conselho Consultivo de Teatro (BRASIL, 1958c, p. 12060).

Nas atas mencionadas podem ser observadas as discussões sobre os critérios e as lutas pela definição de qual teatro subsidiar com recursos públicos, que expressam as tensões artísticas e regionais existentes no campo teatral nessa época. Se em um primeiro momento os representantes do meio teatral, muitos deles vinculados às companhias de comédia cariocas, privilegiaram itens ligados à "tradição", depois, com a inclusão de novos membros - especialmente de figuras engajadas em um "projeto moderno" - os valores estéticos assumiram maior importância, o que acirrou as disputas, incluindo pela própria direção do órgão (CAMARGO, 2017, p. 194, 219-220).

Por fim, as listas de auxílios fornecem o quadro geral dos contemplados, complementando informações ausentes em processos ou até contrapondo-se aos dados encontrados. As listas indicam, ainda, a existência de uma grande variedade de companhias profissionais, grupos amadores, circos-teatros e atividades teatrais em todo o país, em sua maior parte desconhecidos, o que nos lança ao estágio ainda incipiente de nossos estudos sobre a história do teatro no Brasil.

Além desses apontamentos externos, tais processos apresentam uma série de particulares, pois tratam do relacionamento entre companhia, artista, grupo ou entidade e um órgão público. Essa questão evidencia a necessidade de atenção à forma como os pedidos eram feitos, em especial, os destinatários e as justificativas, que precisam ser consideradas à luz dos debates realizados no campo teatral, principalmente no tocante à modernização da cena.

Em relação aos anos iniciais da trajetória do órgão, é necessário assinalar a existência de muitas solicitações endereçadas ao ministro da Educação 
e Saúde e até ao presidente da República, que interferiram diretamente em certas situações, como fizeram outros ministros e presidentes até 1964.

Alguns pedidos contêm informações detalhadas, e outros pouquíssimos elementos. O lançamento dos editais acarretou uma maior padronização, mas, mesmo assim, vale ressaltar as justificativas presentes, que fornecem indícios sobre as estratégias de artistas, grupos etc. para a obtenção do patrocínio oficial de suas iniciativas.

Muitas justificativas basearam-se em argumentos econômicos, com ênfase nas dificuldades em fazer teatro no país ou nos prejuízos sofridos, como foi o caso do Teatro Brasileiro de Comédia (TBC), que pleiteou auxílio em 1958, destacando a realização de espetáculos de "alta categoria" e as perdas consequentes de dois incêndios ocorridos na sede da companhia ${ }^{5}$.

As medidas de atração de público também foram utilizadas com alguma frequência entre as companhias profissionais. Isso pode ser visto, por exemplo, na proposta da Companhia Dulcina-Odilon, apresentada em 1943, de realização de uma temporada com preços populares, distribuição gratuita de ingressos para estudantes e realização de matinês culturais para professores e alunos do ensino secundário (CAMARGO, 2011, p. 171).

Outra justificativa encontrada de forma recorrente foi a da valorização das "qualidades artísticas", pautadas por uma visão hierarquizada dos gêneros teatrais presente nos debates desde o século XIX e expressa em oposições nem sempre definidas claramente, como: "cultura $X$ diversão", "arte $X$ entretenimento" e "erudito X popular". Visão que, em algumas ocasiões, foi utilizada como objetivo das solicitações, como ilustra um processo relativo à Companhia de Dercy Gonçalves, que, em 1958, pediu auxílio visando "poder elevar o padrão das suas montagens"6 (CAMARGO, 2017, p. 14).

Mesmo sem aprofundar a discussão, cabe notar que essas justificativas também permitem perceber como algumas companhias se adequaram, por meio de seus repertórios e de suas práticas, a determinadas orientações governamentais com a finalidade de garantir o amparo oficial. Vale citar o exemplo da encenação pela Companhia Jayme Costa, em 1939, de textos de caráter histórico, que eram favorecidos pelo SNT em consonância

5 PROCESSO no $124.122 / 58$

6 PROCESSO ํㅜ 124.122/58 
às diretrizes oficiais elaboradas pelo governo Vargas durante o Estado Novo (CAMARGO, 2011, p. 161). E a proposta de popularização apresentada pelo Teatro de Arena em 1963, em conformidade com as ideias do diretor Roberto Freire, que privilegiou iniciativas com tais propósitos com verbas mais significativas (CAMARGO, 2017, p. 240).

Pontos semelhantes podem ser encontrados nos pareceres escritos pelos diretores, funcionários ou membros dos organismos responsáveis pela seleção dos beneficiados pelas subvenções. Nestes casos, o uso de tais argumentos serviu para fundamentar os "desvios" frequentes às portarias e aos editais. "Desvios" que incluíram até as exigências legais, em referência, por exemplo, à Lei no 1.565 de 1952, conhecida como "Lei do terço", a qual obrigou a montagem de uma peça brasileira a cada duas estrangeiras (Ibid., p. 203).

A falta de critérios nítidos, o descumprimento das determinações vigentes e o prevalecimento dos interesses pessoais que marcaram algumas concessões contribuíram para tornar essa prática objeto de críticas ao longo dos anos pesquisados. Embora não se tenha realizado uma leitura de todos os processos com pedidos de auxílio para quantificar a proporção entre as demandas e as concessões, foi possível notar que, nos primeiros anos, um número pequeno de companhias, entidades e grupos amadores foi amparado, revelando a existência de uma seleção, mesmo sem critérios delimitados. Tal situação se modificou na década de 1950, quando uma quantidade cada vez maior de beneficiados passou a receber auxílios menores, por vezes irrisórios.

Em resumo, ao limitar a intervenção oficial à ajuda financeira mais do que educacional ou cultural, as direções e a participação institucional do setor forjaram o que chamamos de "modelo residual" de patrocínio (Ibid., p. 154), responsável por acarretar um crescimento de demandas e, uma consequência "inesperada", o aumento da produção documental, que, preservada, apesar das bruscas alterações sofridas pela administração pública brasileira, constitui um vasto conjunto de fontes sobre a história do teatro no Brasil (FARGE, 2009, p. 11). 


\section{Considerações finais}

Neste texto buscamos refletir sobre os usos e algumas possibilidades de pesquisa do acervo do SNT. Para tanto, abordamos a história administrativa do órgão, a fim de compreendermos a sua produção documental, notadamente os processos relacionados à subvenção, e tratamos de aspectos inerentes a esse material, enfatizando algumas características e conteúdos.

Assim, longe de esgotar o assunto, mostramos que os dados apresentados nesses documentos podem fornecer subsídios sobre a relação entre Estado e teatro, e, em particular, sobre as formas de financiamento oficiais, pouco mencionadas ou até "esquecidas" em depoimentos e outros tipos de fontes comumente utilizados nos estudos sobre a história do teatro no Brasil.

Esta análise também aponta para a importância de situar a disputa entre os projetos artísticos para o teatro brasileiro, no contexto da chamada modernização teatral, como disputas políticas, que foram feitas fora e dentro do órgão. Além disso, esses documentos permitem elucidar questões que remetem aos variados fatores interferentes na produção dos espetáculos, não apenas estéticos, mas "técnicos, políticos, econômicos e ideológicos" (GOETSCHEL, 2011), que, a partir do cruzamento com outras fontes, podem contribuir para repensar e reescrever a história do teatro no Brasil.

\section{Referências bibliográficas}

BRANDÃO, T. Uma empresa e seus segredos: companhia Maria Della Costa. São Paulo: Perspectiva, 2009.

BRASIL. Decreto-Lei no 92, de 21 de dezembro de 1937. Cria o Serviço Nacional de

Teatro. Lex: coletânea de legislação e jurisprudência: legislação federal e marginália, São Paulo, v. 1, p. 364, 1937.

Decreto no 43.928, de 26 de junho de 1958. Institui a Campanha Nacional de Teatro. Diário Oficial da União. Poder Executivo, Rio de Janeiro, 26 jun. 1958a. Seção 1, p. 14534.

Decreto no 44.318, de 21 de agosto de 1958. Aprova o Regimento do Serviço Nacional de Teatro, do Ministério da Educação e Cultura. Diário Oficial da União. Poder Executivo, Rio de Janeiro, 23 ago. 1958b. Seção 1, p. 18801. 
Serviço Nacional de Teatro. Edital de 1958. Diário Oficial da República dos Estados Unidos do Brasil. Poder Executivo, Rio de Janeiro, 26 maio 1958c. Seção 1, p. 12060.

CAMARGO, A. R. Em busca de uma política para o desenvolvimento do teatro brasileiro: as experiências da Comissão e do Serviço Nacional de Teatro (19361945). 2011. 234 f. Dissertação (Mestrado em História Social) - Instituto de História, Universidade Federal do Rio de Janeiro, Rio de Janeiro, 2011. Disponível em: <https://goo.gl/wwHKX4>. Acesso em: 22 ago. 2017.

Por um Serviço Nacional de Teatro: debates, projetos e o amparo oficial ao teatro no Brasil (1946-1964). 2017. 397 f. Tese (Doutorado em História Social) Instituto de História, Universidade Federal do Rio de Janeiro, Rio de Janeiro, 2017. Disponível em: <https://goo.gl/YNFHi1>. Acesso em: 22 ago. 2017.

CANTANHEDE, C.; FONTANA, F. Projeto Memória das Artes Cênicas: um breve histórico de um acervo das artes cênicas e algumas considerações metodológicas. In: SIMPÓSIO NACIONAL DE HISTÓRIA, 27, 2013, Natal. Anais... São Paulo: ANPUH - Associação Nacional de História, 2013. Disponível em: <https://goo.gl/ LEVVzQ>. Acesso em: 10 jan. 2017.

CERTEAU, M. A escrita da História. 2. ed. Tradução Maria de Lourdes Menezes. Rio de Janeiro: Forense Universitária, 2000.

COOK, T. Arquivos pessoais e arquivos institucionais: para um entendimento arquivístico comum da formação da memória em um mundo pós-moderno. Revista Estudos Históricos, Rio de Janeiro, v. 11, n. 21, 1998, p. 129-149. Disponível em: <https://goo.gl/LoniyG>. Acesso em: 11 set. 2017.

DUCHEIN, M. O respeito aos fundos em arquivística: princípios teóricos e problemas práticos. Arquivo e Administração, Rio de Janeiro, v. 10-14, n. 1, p. 14-33, abr. 1982/ago. 1986.

FARGE, A. O sabor do arquivo. Tradução Fátima Murad. São Paulo: Edusp, 2009.

FARIA, J. R. (Dir.). História do teatro brasileiro: das origens ao teatro profissional da primeira metade do século XX. São Paulo: Perspectiva; Edições Sesc SP, 2012. v. 1.

História do teatro brasileiro: do modernismo às tendências contemporâneas. São Paulo: Perspectiva; Edições Sesc SP, 2013. v. 2.

FIGARO, R. (Coord.). Na cena paulista, o teatro amador: circuito alternativo e popular de cultura (1927-1945). São Paulo: Ícone, 2008.

FONSECA, M. S. O Arquivo Institucional da Funarte: problemas estruturais. 2007. 46 f. Trabalho de Conclusão de Curso (Especialização em Organização, Planejamento e Direção de Arquivos) - Universidade Federal Fluminense, Niterói, 2007.

FONTANA, F. S. Por um sonho de nação: Paschoal Carlos Magno e o Teatro do Estudante do Brasil. 2014. 381 f. Tese (Doutorado em Artes Cênicas) - Centro de 
Letras e Artes, Universidade Federal do Estado do Rio de Janeiro, Rio de Janeiro, 2014.

GOETSCHEL, P. Archives du "spectacle vivant", usages et écriture de l'histoire. Historiographie \& archivistique. Ecriture et méthodes de l'histoire à l'aune de la mise en archives, sous la direction de Philippe Poirrier et Julie Lauvernier. Territoires Contemporains, Dijon, 2011. Disponível em: <https://goo.gl/CdpBPU>. Acesso em: 4 set. 2017.

GUINSBURG, J.; PATRIOTA, R. Teatro brasileiro: ideias de uma história. São Paulo: Perspectiva, 2012.

MERISIO, P. O circo-teatro. In: FARIA, J. R. (Dir.). História do teatro brasileiro: do modernismo às tendências contemporâneas. São Paulo: Perspectiva; Edições Sesc SP, 2013. p. 433-446.

MICELI, S. Intelectuais à brasileira. São Paulo: Companhia das Letras, 2001.

MOSTAÇO, E. Considerações sobre a história do teatro brasileiro. Revista Sala Preta, São Paulo, v. 15, n. 1, p. 249-264, 2015. Disponível em: <https://goo.gl/ yWwvds>. Acesso em: 25 abr. 2017.

PATRIOTA, R. O teatro e o historiador. In: RAMOS, A. F.; PEIXOTO, F.; PATRIOTA, R. (Orgs.). A história invade a cena. São Paulo: Hucitec, 2008. p. 16-58.

PEREIRA, V. H. A. A musa carrancuda: teatro e poder no Estado Novo. Rio de Janeiro: Fundação Getúlio Vargas, 1998.

PICON-VALLIN, B. Um museu para o teatro. Tradução Elizabeth R. Azevedo. Pitágoras 500. Revista de Estudos Teatrais, Campinas, v. 3, p. 115-127, out. 2012.

RABETTI, M. L.; MACIEL, P. M. C. Itinerários da opereta: do mapeamento de acervos a uma antologia de fontes selecionadas. In: PARANHOS, K. R. (Org.). História, teatro e política. São Paulo: Boitempo, 2012. p. 59-80.

SEMINÁRIO DE PRESERVAÇÃO DE ACERVOS TEATRAIS, 1., 2012, São Paulo. Anais... São Paulo: USP-PRCEU; TUSP; LIM CAC, 2015. 164 p. Disponível em: <https://goo.gl/7rks8M>. Acesso em: 14 set. 2017.

Recebido em 30/09/2017

Aprovado em 21/10/2017

Publicado em 26/12/2017 